\title{
Functional identification of an antennal lobe DM4 projection neuron of the fruit fly
}

\author{
Aurel A Lazar, ${ }^{*}$ Chung-Heng Yeh \\ From The Twenty Third Annual Computational Neuroscience Meeting: CNS*2014 \\ Québec City, Canada. 26-31 July 2014
}

A rich set of genetic tools and extensive anatomical data make the olfactory system of the fruit fly a neural circuit of choice for studying function in sensory systems. Though a substantial amount of work has been published on the neural coding of olfactory sensory neurons (OSNs) of the fruit fly, yet little is known how projection neurons (PNs) encode time-varying odor stimuli [1]. Here we address this question with in vivo experiments coupled with a phenomenological characterization of the spiking activity of PNs.

Recently, a new class of identification algorithms called Channel Identification Machines (CIMs) [2] was proposed for identifying dendritic processing in simple neural circuits using conditional phase response curves (cPRCs) [3]. By combining cPRCs with the reduced project-integrated-and- fire neuron (PIF) model [4], the CIM algorithms identify a complete phenomenological description of spike generation of a biological neuron for weak to moderately strong stimuli. Moreover, the identification method employed does not require white noise stimuli nor an infinitesimal pulse injection protocol as widely used in the past [5].

Here we identify the PNs both in silico and in vivo. Starting with simulations, we investigate the feasibility of the CIM method on PNs modeled as pseudo uni-polar neurons in silico, as shown in Figures 1.(B) and 1.(C). We then systematically convert the CIM method into a stepby-step experimental protocol, and carry it out in vivo by injecting currents into PNs using the patch clamping technique [6,7]. A snapshot of PN patching is depicted in Figure 1.(A).

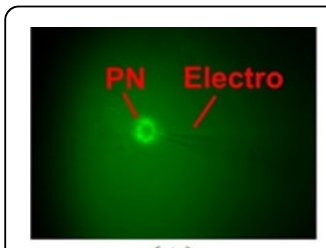

(A)

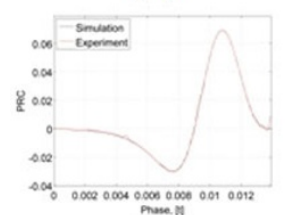

(F)

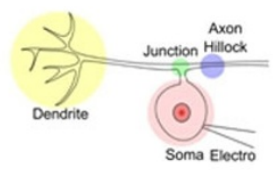

(B)

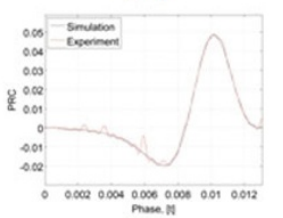

$(\mathrm{G})$

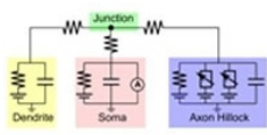

(C)

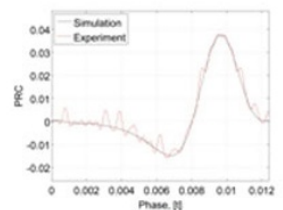

$(\mathrm{H})$

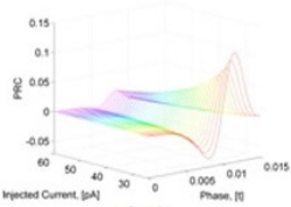

(D)

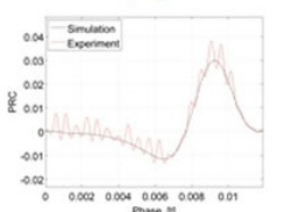

(I)

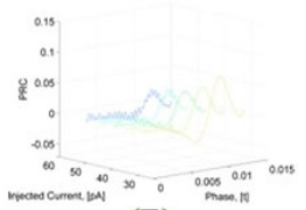

(E)

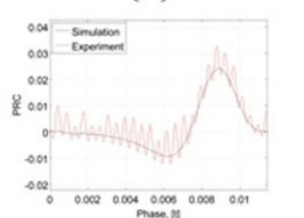

$(\mathrm{J})$

Figure 1 (A) PN with GFP expression under 60x magnification; (B) Schematic of the anatomy of the PN; (C) Circuit diagram of the simulated PN model; (D) Identified PRC of the simulated PN model; The injected current varies from 25 [pA] to 60 [pA] with step size 1 [pA]; (E) Identified PRC of PN. The injected current varies from $30[\mathrm{pA}]$ to $50[\mathrm{pA}]$ with step size 5 [pA]; (F-J) Comparison between identified PRC of simulated PN model and the in vivo PN; Injected current value is $30[\mathrm{pA}]$ to $50[\mathrm{pA}]$ with step size $5[\mathrm{pA}]$ from (F) to (J). Time is in seconds.

\footnotetext{
* Correspondence: aurel@ee.columbia.edu

Department of Electrical Engineering, Columbia University, New York, NY 10027, USA
}

\section{) Biomed Central}

(c) 2014 Lazar and Yeh; licensee BioMed Central Ltd. This is an Open Access article distributed under the terms of the Creative Commons Attribution License (http://creativecommons.org/licenses/by/4.0), which permits unrestricted use, distribution, and reproduction in any medium, provided the original work is properly cited. The Creative Commons Public Domain Dedication waiver (http://creativecommons.org/publicdomain/zero/1.0/) applies to the data made available in this article, unless otherwise stated. 
We demonstrate that the CIM method accurately identifies the cPRCs of the in silico PN model for a wide range of bias currents, as shown in Figure 1.(D). Moreover, the new method also accurately identifies a set of cPRCs of PNs in vivo, as shown in Figure 1.(E). For comparison, we tune the identified cPRCs of the in silico PN model to fit the in vivo identified cPRCs of biological PNs. We demonstrate that: (i) the new method accurately identifies the cPRCs of PNs for small bias currents; (ii) the accuracy of the cPRC is qualitatively lower during the refractory period, as depicted in Figures 1.(F-J).

Published: 21 July 2014

\section{References}

1. Wilson Rl: Early olfactory processing in Drosophila: mechanisms and principles. Annual Review of Neuroscience 2013, 36:217-41.

2. Lazar AA, Slutskiy YB: Functional identification of spike-processing neural circuits. Neural Computation 2014, 26(2):264-305.

3. Kim AJ, Lazar AA: Recovery of stimuli encoded with a Hodgkin-Huxley neuron using conditional PRCs. Phase Response Curves in Neuroscience Springer; 2012, 257-277.

4. Lazar AA: Population encoding with Hodgkin-Huxley neurons. IEEE Transactions on Information Theory 2010, 56(2).

5. Netoff T, Schwemmer MA, Lewis TJ: Experimentally estimating phase response curves of neurons: theoretical and practical issues. In Phase Response Curves in Neuroscience. Volume 6. Springer; 2012:95-129.

6. RTXI: Experiments were performed using the real-time experiment interface. [http://www.rtxi.org].

7. Kim AJ, Lazar AA, Slutskiy YB: Drosophila projection neurons encode the acceleration of time-varying odor waveforms. Computational and Systems Neuroscience Meeting Salt Lake City, UT; 2011.

\section{doi:10.1186/1471-2202-15-S1-P5}

Cite this article as: Lazar and Yeh: Functional identification of an antennal lobe DM4 projection neuron of the fruit fly. BMC Neuroscience 2014 15(Suppl 1):P5.

\section{Submit your next manuscript to BioMed Central} and take full advantage of:

- Convenient online submission

- Thorough peer review

- No space constraints or color figure charges

- Immediate publication on acceptance

- Inclusion in PubMed, CAS, Scopus and Google Scholar

- Research which is freely available for redistribution

Submit your manuscript at www.biomedcentral.com/submit 